\title{
社会科学进展
}

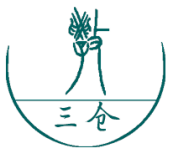

sciscan

\section{北京市普惠性学前教育发展的 措施建议}

\author{
包路林 ${ }^{*}$ 卫 蓝
}

北京北咨城市规划设计研究院有限公司, 北京, 100031

邮箱: baolulin@126.com

摘 要：为了解决当前学前教育存在的入园难、入园贵的问题, 发展普惠性学 前教育势在必行。本文在总结当前北京市普惠性学前教育发展的现状与问题的 基础之上, 提出大力发展普惠性学前教育的若千措施建议, 为缓解北京市学前 教育供需矛盾，快速发展学前教育提供参考。

关键词：普惠性幼儿园；措施建议；北京市

收稿日期：2019-06-03; 录用日期：2019-07-28；发表日期：2019-08-02

\section{Suggestions on Inclusive Preschool Education in Beijing}

\author{
Bao Lulin* Wei Lan
}

Beijing Beizi Urban Planning Institute Co., Ltd., Beijing 100031

Abstract: In order to relieve the difficulties of preschool entrance and the high price

文章引用: 包路林, 卫蓝. 北京市普惠性学前教育发展的措施建议 $[J]$. 社会科学进展, 2019, 1 ( 2 ) : 
problems, it is imperative to develop the inclusive preschool education in Beijing. The article concludes the current status and existing problems, and put forward suggestions in preschool education in Beijing, which is beneficial to solving the imbalance of supply and demand, and supporting the quick development of preschool education in Beijing.

Key words: Inclusive Preschool Education; Suggestions; Beijing

Received: 2019-06-03; Accepted: 2019-07-28; Published 2019-08-02

Copyright ( 2019 by author(s) and SciScan Publishing Limited

This work is licensed under a Creative Commons Attribution 4.0 International License. https://creativecommons.org/licenses/by/4.0/

普惠性幼儿园是面向大众、收费较低、保教质量有保障的幼儿园。2010年《国 务院关于当前发展学前教育的若干意见》（国发〔2010]41号）指出：发展学 前教育必须坚持公益性和普惠性，正式提出普惠性学前教育。普惠性幼儿园的 界定尚无统一标准，当前北京市主要将公办幼儿园和月收费 2000 元以下的民办 幼儿园作为普惠性幼儿园统计。

\section{1 普惠性幼儿园基本情况}

根据研究调研数据，截至 2017 年 10 月底，北京市公办幼儿园和普惠性民 办幼儿园共计有 1130 个，班级总数 1.12 万个，在园幼儿总数 33.53 万人，教职 工总数 4.89 万人，其中专任教师总数 2.81 万人（见表 1 ）。 
表 1 北京市公办幼儿园和普惠性民办幼儿园基本情况

Table 1 The Basic Information of Official and Inclusive Preschool Education in Beijing

\begin{tabular}{llllll}
\hline 幼儿园性质 & $\begin{array}{l}\text { 幼儿园 } \\
\text { 数量 }(\text { 个) }\end{array}$ & $\begin{array}{l}\text { 班级 } \\
\text { 数量 }(\text { 个) })\end{array}$ & $\begin{array}{l}\text { 在园幼儿 } \\
\text { 总数 (人) }\end{array}$ & $\begin{array}{l}\text { 教职工 } \\
\text { 总数 (人) }\end{array}$ & $\begin{array}{l}\text { 专任教师 } \\
\text { 总数 (人) }\end{array}$ \\
\hline 公办幼儿园 & 883 & 9012 & 276519 & 39426 & 23598 \\
普惠性民办幼儿园 & 247 & 2209 & 58795 & 9434 & 4545 \\
合计 & 1130 & 11221 & 335314 & 48860 & 28143 \\
\hline
\end{tabular}

\section{1 公办幼儿园基本情况}

截至 2017 年 10 月底, 北京市公办幼儿园共计 883 个, 班级总数 9012 个, 在园幼儿总数 276519 人，教职工总数 39426 人，其中专任教师总数 23598 人。

从各区来看，幼儿园数量超过 100 个的有海淀区和朝阳区，分别为 121 个 和 102 个，其中海淀区在各个区中数量最多; 数量最少的是石景山区，为 20 个。 海淀区和朝阳区的班级总数均超过了 1000 个，分别为 1661 个和 1166 个; 门头 沟区的班级总数最少，为 146 个 (见图 1 ) 。海淀区在园幼儿总数达到了 52377 人, 是幼儿总数最多的区, 比较来看, 门头沟区的幼儿总数最少, 为 3849 人 (见 图 2 ）。教职工总数与专任教师总数的分布趋势基本相同，以海淀区最多，分别 为 8830 人和 4300 人，最少的为门头沟区，分别为 606 人和 402 人（见图 3 ）。 通过数据的分析比较, 海淀区的幼儿园数量、班级总数、在园幼儿总数、教职 工总数和专任教师总数均为各区中最多。

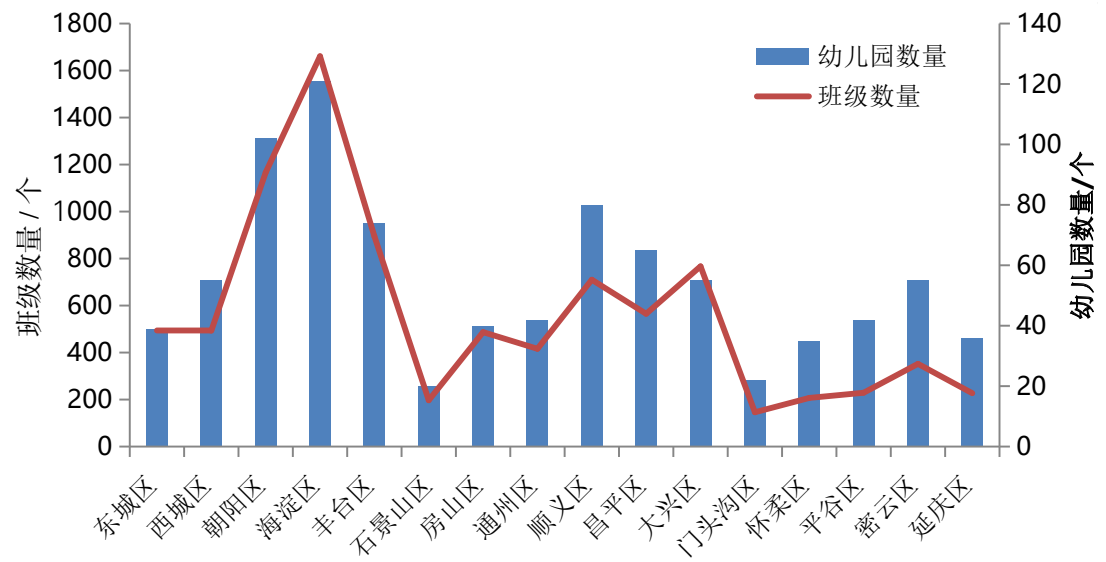

图 1 各区公办幼儿数量和班级数量

Figure 1 The Number of Schools and Classes in Official Preschool in Each District 


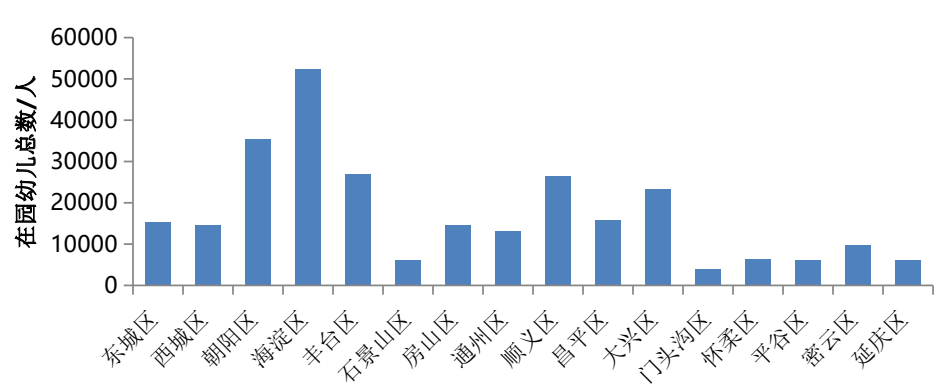

图 2 各区公办幼儿园在园幼儿总数

Figure 2 The Number of Children in Official Preschool in Each District

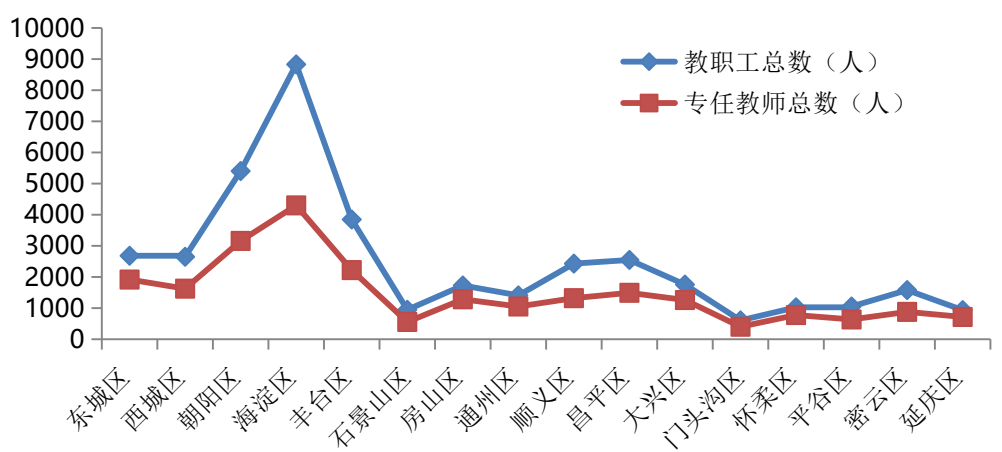

图 3 各区公办幼儿园教职工和专任教师总数

Figure 3 The Number of Teachers and Staffs in Official Preschool in Each District

\section{2 普惠性民办幼儿园基本情况}

截至 2017 年 10 月底, 北京市普惠性民办幼儿园共计 247 个, 班级总数 2209 个, 在园幼儿总数 58795 人, 教职工总数 9434 人, 其中专任教师总数 4545 人。 当前全市普惠性幼儿园平均月收费标准为 1220 元。

从各区来看，朝阳区普惠性民办幼儿园数量最多，为 45 个，西城区、海淀 区没有民办普惠性幼儿园，东城区仅有 1 个。班级总数同样以朝阳区最多，为 668 个 ( 见图 4 )。在园幼儿总数中, 超过 10000 人的仅有朝阳区, 房山区、昌平区、 大兴区幼儿数量超过 5000 人（见图 5 ）。教职工总数和专任教师总数的各区分 布情况基本相同，朝阳区为 3072 人和 1467 人，在各区中占据首位（见图 6 ）。 通过数据的分析和比较, 在普惠性民办幼儿园中, 朝阳区在各方面的数量均最多。 

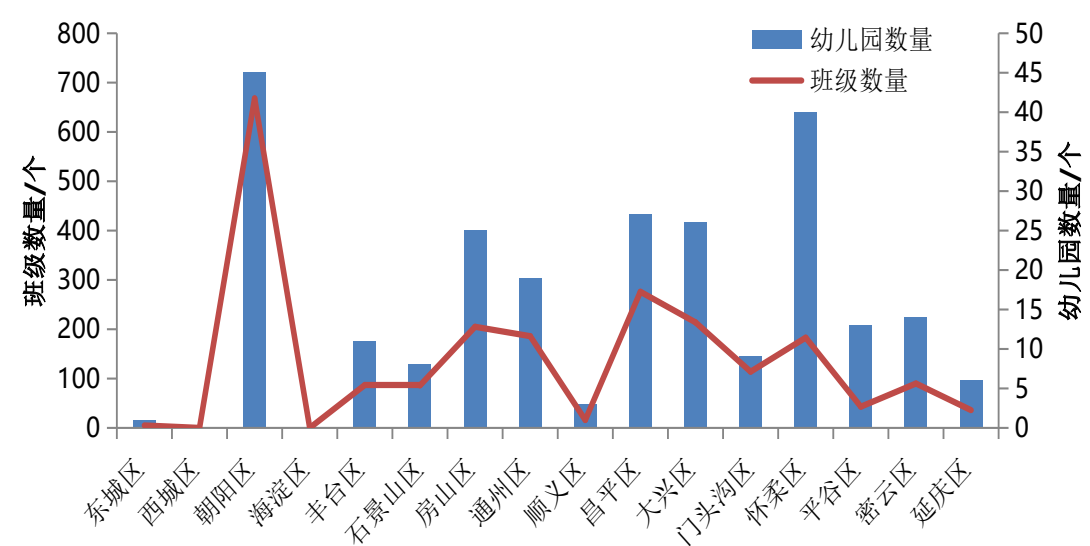

图 4 各区普惠性民办幼儿园数量和班级数量

Figure 4 The Number of Schools and Classes in Inclusive Preschool in Each District

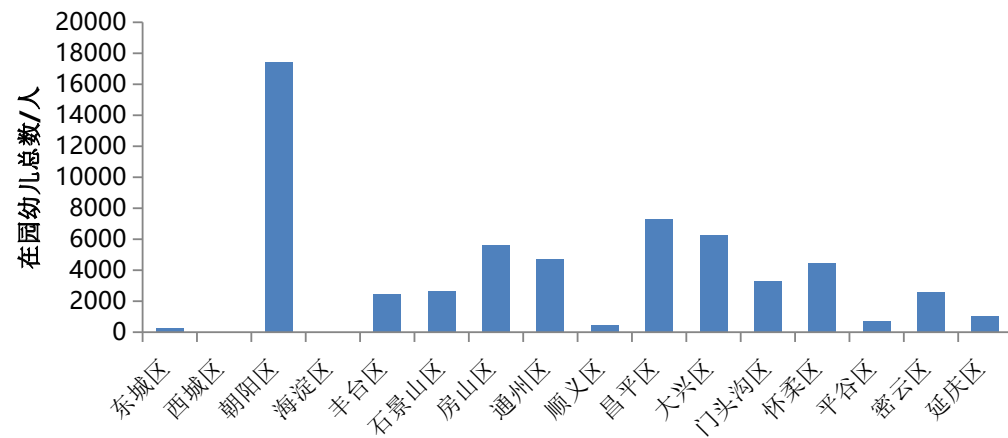

图 5 各区普惠性民办幼儿园在园幼儿总数

Figure 5 The Number of Children in Inclusive Preschool in Each District

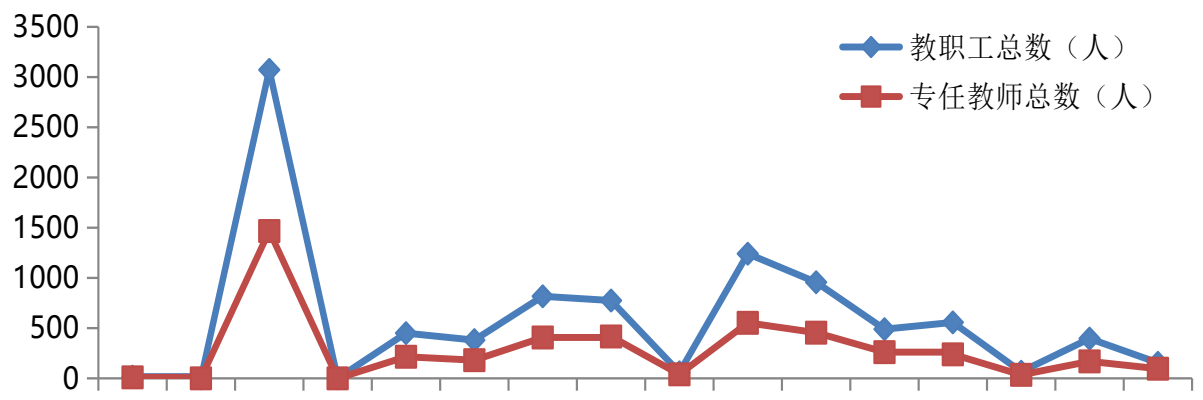

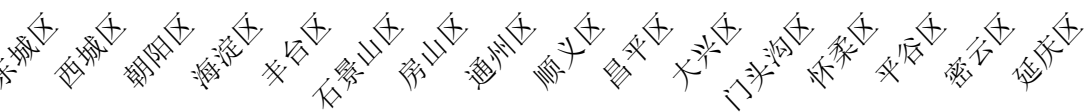

图 6 各区普惠性幼儿园教职工和专任教师总数

Figure 6 The Number of Teachers and Staffs in Inclusive Preschool in Each District 


\section{2 当前存在的主要问题}

\section{1 普惠性民办幼儿园总量不足}

北京市普惠性民办幼儿园总量为 247 所，仅占全市所有幼儿园（2098 所） 的 $12 \%$ ，占公办和普惠性民办幼儿园总量的 $22 \%$ ，公办幼儿园和普惠性民办幼 儿园的比例为 3.57:1, 普惠性民办幼儿园总量明显不足。从在园幼儿调研数据来 看, 普惠性幼儿园在园幼儿总量为 5.9 万人，占全市所有在园幼儿数 ( 41.7 万人) 的 $14 \%$ ，占公办和普惠性民办园幼儿总量的 $18 \%$ ，公办幼儿园和普惠性民办幼 儿园的在园幼儿比例为 4.7:1, 普惠性民办幼儿园所能容纳的学位数量有限, 与 公办幼儿园还存在很大差距。从各区分布来看，西城区、海淀区两个适龄儿童 数量很多的区没有普惠性幼儿园，东城区仅有一所普惠性民办幼儿园，顺义区、 延庆区数量也很少。

\section{2 各区对普惠性幼儿园建设意愿不强}

本次调研中了解到, 各区普遍对普惠性幼儿园建设意愿不强, 对于在建或 者未来规划建设的幼儿园项目是否确定为普惠性幼儿园多数还不能确定。各区 不能确定普惠性幼儿园建设的原因主要是认为普惠性幼儿园的补贴标准难以实 现收益平衡。北京市普惠性幼儿园收费一直按照 2000 元 / 生月以内执行，部分 民办普惠性幼儿园根据《北京市扶持学前教育事业发展项目经费管理办法》, 能够得到财政补助资金 (平均 450 元 / 生月 )。普惠性民办幼儿园的办园成本 (包 括房租、人工、设施设备等) 平均约为 2000 2500 元 / 生月。因此按照现行收费 标准，普惠性民办幼儿园基本实现收支平衡。当前公办幼儿园则根据幼儿园的 五个级别（示范园、一级、二级、三级、无级），收费从 200 900 元 / 生月不等 (分别为 900 元 / 生月、750 元/生月、600 元/生月、450 元/生月、200 元/生 月 ）。如果按照普惠性幼儿园与公办幼儿园 “统一办园标准、统一收费标准、 统一财政补贴标准” 的 “三统一” 新要求，普惠性民办幼儿园收费将大大降低， 收支不能实现平衡。因此，各区对于普惠性民办幼儿园建设还持观望态度。这 就形成了政府大力推进普惠性幼儿园的意志和幼儿园对于收支平衡的顾虑之间 
的矛盾。

\section{3 用地标准方面存在发展瓶颈}

2017 年开始，全国实施新的《幼儿园建设标准》（建标 175-2016）。新标 准要求 “室外地面游戏场地人均面积不应低于 4 平方米”，“幼儿园绿地率不 宜低于 $30 \%$ ，人均集中绿地面积不应低于 2 平方米”，并规定了幼儿园活动用 房、服务用房、附属用房的人均使用面积的上下限。北京市用地资源紧张，尤 其是东城区、西城区，在新增教育用地难以满足的情况下，按照新的建设标准， 现有用地指标难以保障学位增加的需求。例如，一处 4000 平方米用地按照原标 准能够建设 12 个班的幼儿园，但按照新的建设标准只能建设 9 个班的幼儿园， 与当前扩大学位供给的要求形成了较大矛盾。

\section{3 下一步工作建议}

根据国家第三期学前教育行动计划 “普惠性幼儿园覆盖率 ( 公办幼儿园和 普惠性民办幼儿园在园幼儿数占在园幼儿总数的比例 ) 达到 $80 \%$ 左右”。北京 市应落实这一要求，全力加快普惠性幼儿园发展，提供 “广覆盖、保基本” 的 学前教育公共服务。

\section{1 明确普惠性幼儿园的制度设计}

北京市应制定普惠性民办学前教育机构认定标准，明确普惠性幼儿园的质 量标准、收费标准、补贴标准，逐年确定一批普惠性民办幼儿园。各级政府把 建设普惠性幼儿园建设工作纳人社会事业发展总体规划考核。将提供普惠性学 位数量和办园质量作纳人区级政府绩效考核。鼓励有积极性的机关和企事业单 位、集团、高校、部队等单位恢复或新开办幼儿园，充分发挥街道、乡镇在新建、 改扩建幼儿园中的作用。街道腾退空间、首都非核心功能疏解后腾退的空间优 先用于学前教育，每个街道通过自办或委托等方式至少新办一所普惠性幼儿园 和托儿所。通过政府购买服务、补贴租金、减免租金、综合奖补、派驻公办教师、 培训教师、教研指导等方式，加快民办普惠性幼儿园发展。对于西城区、海淀 
区等没有普惠性幼儿园的区，应重点加大普惠性幼儿园建设支持力度，推进普 惠性幼儿园在各区的合理分布。

\section{2 加大对普惠性幼儿园的财政补助}

普惠性幼儿园的推进工作无法通过单一的政府部门来实现，甚至无法仅通 过政府的力量来实现。在推广的初期阶段，市级各部门应形成合力，将普惠性 幼儿园建设作为近三年一项重点任务严抓落实。为了更好地实现普惠性幼儿园 的建设效果，应重点推进社区内普惠性幼儿园建设，满足群众就近便捷人园的 需求。除了即将出台的《北京市市对区促进基础教育事业发展 (学前阶段) 专 项转移支付资金管理办法》的支持政策之外，为激发民办机构、民营资本的办 园意愿，应研究制定《普惠性幼儿园基本建设费用补助办法》，明确新建、改 扩建为普惠性幼儿园项目的市区级固定资产投资支持的范围、规模和监管等内 容; 应研究制定《学前教育社区办园点基本建设费用补助办法》, 明确对于社 区配套办园项目的市区级固定资产投资支持的范围、规模和监管等内容; 应研 究制定《未注册园改造项目基本建设费用补助办法》，明确市区级固定资产投 资支持的范围、规模和监管等内容。此外，教育部门、财政部门应出台相应的 师资补助等方面的政策。通过一系列财政补助政策，消除幼儿园，主要是民办 幼儿园对于普惠性导致的收支平衡问题的顾虑，推动更多民办机构加人普惠性 幼儿园的队伍中来，提高民办普惠性幼儿园的比例。

\section{3 积极鼓励社区办园的模式}

2015 年开始，根据《关于印发 “北京市居住公共服务设施配置指标” 和 “北 京市居住公共服务设施配置指标实施意见” 的通知》（京政发〔2015] 7 号）, 北京市各小区配套幼儿园基本能够按照规范建成、移交和投人使用。但在 2015 年之前，很多小区配套幼儿园没有建设和移交，形成历史遗留问题。

结合当前学前教育供需矛盾现状，应就近满足社区居民多样化托幼需求， 全面推进街道和社区举办学前教育机构。对于历史遗留的问题, 应系统梳理小 区配套园历史欠账，根据用地、开发商、移交情况等几个方面的情况进行分类， 
针对不同分类给予不同的建设支持，推进学前教育就近人园。对于人园压力大、 土地资源紧张的中心城区及城乡结合部地区，建设一批学前教育社区办园点。 效仿社区养老服务设施建设，制定社区学前教育服务设施建设指导意见。

可采取教育指导、街办监管、社区举办、独立经营、自负盈亏的经营模式， 鼓励社区举办 “社区育儿中心” “社区托儿所” “社区学前教育服务中心”等。 为保证学龄前儿童都能在规范的机构接受学前教育, 按照国家规定, 对具备办 学条件, 达到设置标准的给予登记注册、备案。按照 “谁举办, 谁负责” 的原则, 社区作为举办主体负责幼儿园的日常运营、安全、管理, 街道负责对幼儿园的 监督检查，区教委负责幼儿园的业务指导。社区可向所在乡街、教育部门提出 举办幼儿园申请, 申请的幼儿园需要在场地、人员、园舍等方面符合规范要求, 主要包括必须设置在安全区域内，严禁在污染区和危险区，在集体土地上的自 建房屋内和居民楼内举办; 必须有与保育、教育的要求相适应的园舍和设施, 且必须符合国家的卫生标准和安全标准；保教人员应当符合规定的任职资格和 条件。对具备办学条件, 达到设置标准的社区幼儿园, 注册备案后, 可到有关 部门办理《收费许可证》等相关手续。

\section{4 合理确定普惠性幼儿园的收费标准}

普惠性幼儿园的推进是个长期不解的工作，如果一直依靠财政投人来维持, 随着二胎政策放开等导致的人园幼儿的增加，将成为过大的财政负担。因此， 需要研究按照非义务教育阶段家庭合理分担教育成本的原则，研究制定普惠性 幼儿园生均经费标准和生均财政拨款标准。长期来看，市区两级财政应将学前 教育经费列人财政预算，新增教育经费要向普惠性学前教育倾斜。财政性学前 教育经费在同级财政性教育经费中要占合理比例，应有明显提高。通过政府购 买岗位等方式解决幼儿园教师和保育员、保健员短缺问题，着力补足配齐幼儿 园教职工。为了更长久地实现普惠性幼儿园的健康运营，建议可以开始考虑参 照义务教育生均经费标准，对普惠性民办幼儿园给予补贴。

财政补助的长期政策落实后，普惠性幼儿园还需要通过收费来实现健康运 营。幼儿园收费应接受政府限价，但建议暂时不和公办幼儿园接轨。因为普惠 
性幼儿园的办学成本和公办幼儿园无法媲美, 与公办幼儿园相比, 普惠性幼儿 园的房屋使用成本、人员薪酬、设施维护成本是无法摆脱的三大负担, 如果要 求和公办幼儿园同样的收费，必将导致普惠性幼儿园的流失或者办学质量的下 降。因此, 建议收费标准定位在 1000 2000 元/月左右。根据现状收费调查结果, 可以分区域设置不同的收费标准，中心城区、郊区可以有不同的收费指导方案， 对于中心城区，考虑到房屋租金等成本，可以适当提高收费标准。

\section{5 积极推进未注册幼儿园转变为普惠性幼儿园}

虽然国家有规定 “未取得办园许可证和未办理登记注册手续, 任何单位和 个人不得举办幼儿园”, 但由于学前教育学位总量不足, 还是存在很多未注册 园招收幼儿。当前政府部门正在全力整治这一类型的幼儿园，根据市教委统计， 未注册幼儿园中的幼儿总数接近正规幼儿园幼儿数量的四成, 成为学前教育绝 对不可忽视的重大问题。多数未注册幼儿园均存在一定程度的消防、卫生等方 面的安全隐患问题, 需要通过装修改造措施达到《北京市幼儿园办园条件基本 标准》或《北京市举办小规模幼儿园暂行规定》的要求。建议对于以上正在办 理审批手续和可保留的未注册幼儿园给予装修改造的专项财政资金支持, 使得 这些园所中幼儿接受正规的学前教育。支持标准可参照上述社区办园的设施改 造费用标准执行，同时建议改造后的无证园按照普惠性民办幼儿园统一管理。

\section{参考文献}

[1]王娅, 宋映泉. “幼有所育” 中政府普惠性投人的必然性一一来自六省县 级面板数据的历史证据 $[\mathrm{J}]$. 学前教育研究, 2019,6 .

[2] 虞永平. 普惠性学前教育必须追求优质 [ J ] . 中国教育报，2019，4.

[3] 胡慧婷, 赵雯娟. 普惠性学前教育实现路径分析 [ J ] . 经贸实践, 2017，9.

[4] 王东. 普惠性学前教育：内涵与政策意蕴 $[\mathrm{J}]$. 教育科学, 2014, 4.

[5]祝贺. 地方政府应如何促进普惠性民办园的发展一一来自美国学前教育 PPP 模式的经验 $[\mathrm{J}]$. 教育发展研究，2016，10. 